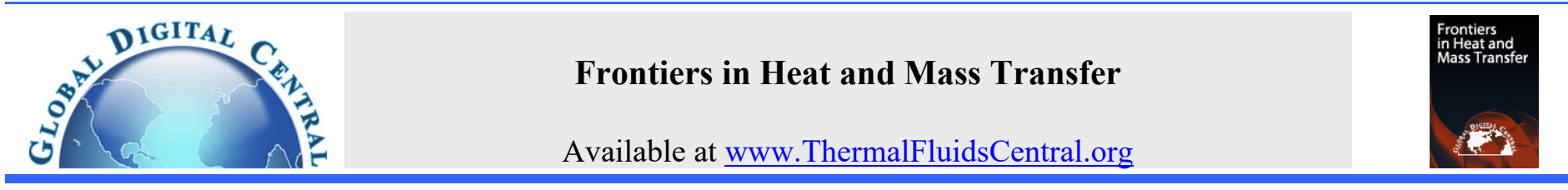

\title{
REVIEW OF VARIOUS THIN HEAT SPREADER VAPOR CHAMBER DESIGNS, PERFORMANCE, LIFETIME RELIABILITY AND APPLICATION
}

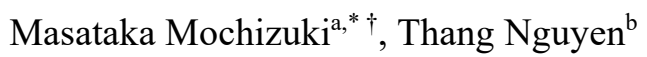 \\ ${ }^{a}$ The Heat Pipe, 1-4-33-1022 Shiohama, Koto-ku, Tokyo 135-0043, Japan \\ ${ }^{b}$ Fujikura Ltd, 1-5-1 Kiba, Koto-ku, Tokyo 135-8512, Japan
}

\begin{abstract}
The cooling device for computers and electronics is getting smaller and thinner year after year, especially for the mobile handheld device such as smartphone which is the most popular gadget and widely use nowadays. It seems that in the current trend every 6-12 months a new model of smartphone is introduced and it was packed with faster processing processor, memories, and graphics, higher density battery, higher resolution for camera and video and so on. The drawback is the device getting hotter due to the increase of heat dissipation caused by faster computing. The traditional method of cooling by purely metal heat conducting is no longer viable. In the recent year thin heat pipes had been introduced to smartphone for better transfer and spreading the heat for cooling. Thin heat spreader vapor chamber becoming more attractive for smartphone cooling due to its potential superior heat transfer than thin heat pipe. Typically heat pipe or vapor chamber for cooling smart phone is less than 0.4 mm thick. This paper is a review and comparison on the structural design and thermal performance of various thin heat spreader vapor chambers on development or available off the shelves. Discussion on material compatibility, non-condensable gas generation and lifetime reliability of heat pipe and vapor chamber will be also included. Lastly some examples of application presented.
\end{abstract}

Keywords: Heat pipes; Vapor chamber; Two-phases heat transfer; Smartphone cooling; Non-condensable gas; Life time reliability.

\section{INTRODUCTION}

The cooling device for computers and electronics is getting smaller and thinner, especially in mobile device like smart phone. In general, the cooling device thickness is less than $0.4 \mathrm{~mm}$. Usually, heat pipe and vapor chamber maximum heat transfer is governed by the capillary limit. However, due to the narrow internal space, other limits can be dominated such as viscous, sonic, entrainment or boiling. In this paper the following topics will be discussed - (i) Theoretical calculation for heat transfer limits for case study; (ii) A review and comparison on the structural design and thermal performance of various thin vapor chambers on development or available off the shelves; (iii) Discussion on material compatibility, non-condensable gas generation and lifetime reliability and (iv) Application.

\section{HEAT TRANSFER LIMITS}

Normally heat pipe and vapor chamber maximum heat transfer is governed by the capillary limit. However, due to the small internal space, other limits can be dominant such as viscous, sonic, entrainment or boiling. Equations and correlations to estimate these limiting factors are listed in Fig. 1 (Yong li, et al., 2016). Authors had assumed that these equations are applicable to flatten heat pipe or vapor chamber configuration. A case study of vapor chamber of length $140 \mathrm{~mm}$ and width $70 \mathrm{~mm}$ has been chosen to represent general dimensions of smartphone. Figure 2(a) showed the calculation results of heat transfer limit calculation for water at $60{ }^{\circ} \mathrm{C}$, for these limiting factors against internal vapor space height. The height is the vapor space without taking account of the wick and container thicknesses. The calculation results indicated that the capillary limit is still a dominant factor, but as the height reduces, the viscous limit can also be a major influence factor. The capillary limit calculation is based on the assumption of sintered copper powder of thickness $0.1 \mathrm{~mm}$, approximate $100 \mathrm{um}$ powder diameter, $60 \%$ porosity, 60 degrees contact angle and water as working fluid. It showed that the limit of the vapor space height is about $0.1 \mathrm{~mm}$ with maximum heat transfer between 1-6W. Figure 2(b) showed the maximum heat transfer vs. space width, keeping the height constant $0.15 \mathrm{~mm}$. As expected if reduced cross sectional area of vapor space then maximum heat transfer would also be reduced.

$$
\begin{aligned}
& Q_{\text {viscous }}=\frac{d_{v}^{2} h_{f g}}{64 \mu_{v} l_{\text {eff }}} \rho_{v} p_{v} A_{v} \\
& Q_{\text {sonic }}=A_{v} \rho_{v} h_{f g}\left[\frac{\gamma \lambda T_{e}}{2 M(\gamma+1)}\right]^{1 / 2} \\
& Q_{\text {entrainment }}=A_{v} h_{f g}\left(\frac{\rho_{v} \sigma}{2 r_{h}}\right)^{1 / 2} \\
& Q_{\text {capillary }}=\frac{\frac{2 \sigma \cos \alpha}{r_{w}}}{\left(\frac{32 \mu_{v} l_{\text {eff }}}{d_{v}^{2} A_{v} \rho_{v} h_{f g}}\right)+\left(\frac{\mu_{l} l_{e f f}}{K A_{w} h_{f g} \rho_{l}}\right)} \\
& Q_{\text {boiling }}=\frac{A_{v} k_{\text {eff }} T_{v}}{\delta h_{f g} \rho_{v}}\left(\frac{2 \sigma}{R_{n}}-\Delta p\right)
\end{aligned}
$$

Fig. 1 Heat transfer limits 


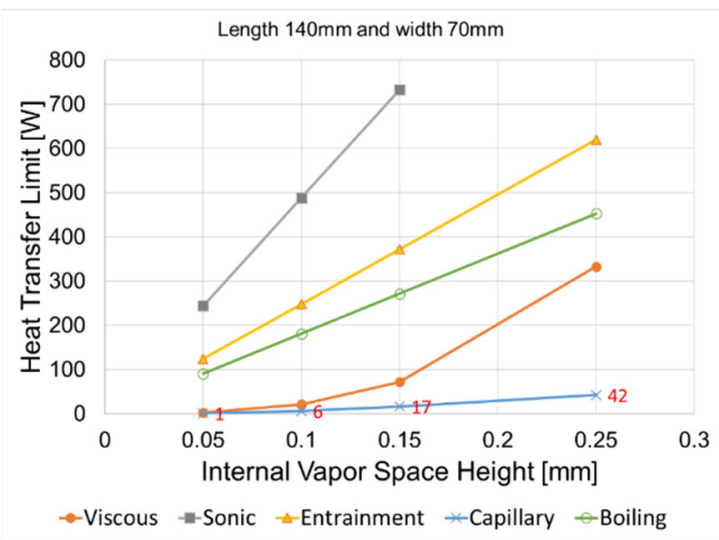

(a)

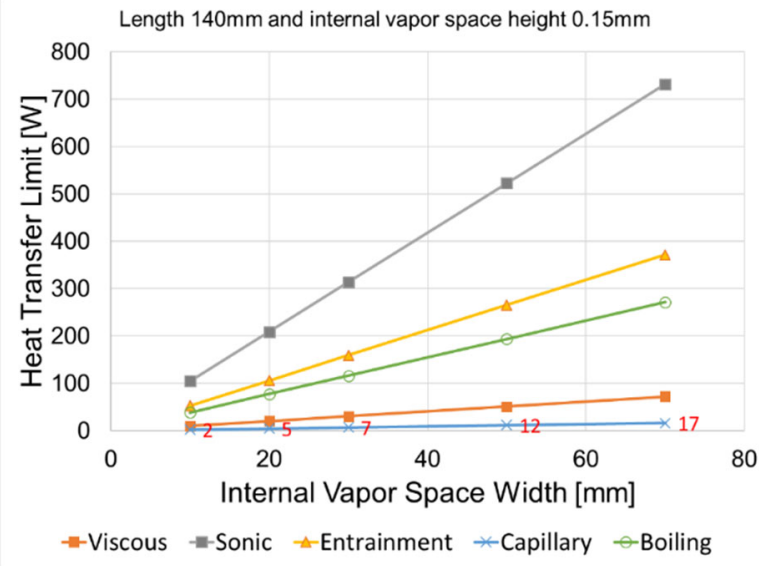

(b)

Fig. 2 Heat transfer limit: (a) internal vapor space height, (b) internal vapor space width

\section{EXAMPLES OF VAPOR CHAMBER}

There are numerous variety designs of vapor chamber either in development phases or available off the shelves to suit particular need. In this paper, a few vapor chambers are selected to show the variation. Figure 3 is a flexible vapor chamber developed by University of Colorado Boulder and Kelvin Thermal Technologies (Bar Cohen et al., 2015; Ryan Lewis, 2016). They have developed 4 major configurations - (a) PCB-based, $3 \mathrm{~cm} \times 3 \mathrm{~cm}$ with effective thermal conductivities claimed to be higher than $1500 \mathrm{~W} / \mathrm{mK}$; (b) Mylar-Aluminum, $5 \mathrm{~cm} \times$ $9.5 \mathrm{~cm}$ with desired flexibility of highly bendable; (c) Copper-cladded Kapton, $5 \mathrm{~cm} \times 9.5 \mathrm{~cm}$ with the desired flexibility and durability and best thermal performance; and (d) All-polymer $5 \mathrm{~cm} \times 9.5 \mathrm{~cm}$. The outer casing is Kapton and the inside has nylon spacers and polymer wicking structure. The best thermal performance (case c) of the vapor chamber has a total thermal resistance of about $1{ }^{\circ} \mathrm{C} / \mathrm{W}$ at heat input of $20 \mathrm{~W}$, and heating area of $1 \mathrm{~cm} \times 1 \mathrm{~cm}$.

In the vapor chamber, the wick structure is the most important design because it governs the capillary force which assist to circulate the working fluid, and distribution the fluid within the vapor chamber. Figure 4 shows various hybrid wick structures for the evaporator of the vapor chamber (Hwang, et al., 2010; Sungtaek, et al., 2013). The wick structures are (a) Powder vertical columnar arteries; (b) Powder converging lateral arteries; and (c) Powder bi-porous structure. The main aim of these structures is to distribute the working fluid to the evaporator efficiently. It was found that all these liquid supply structures showed nearly identical performance. The heat transfer is dominated by the evaporation of the spreading liquid layers.

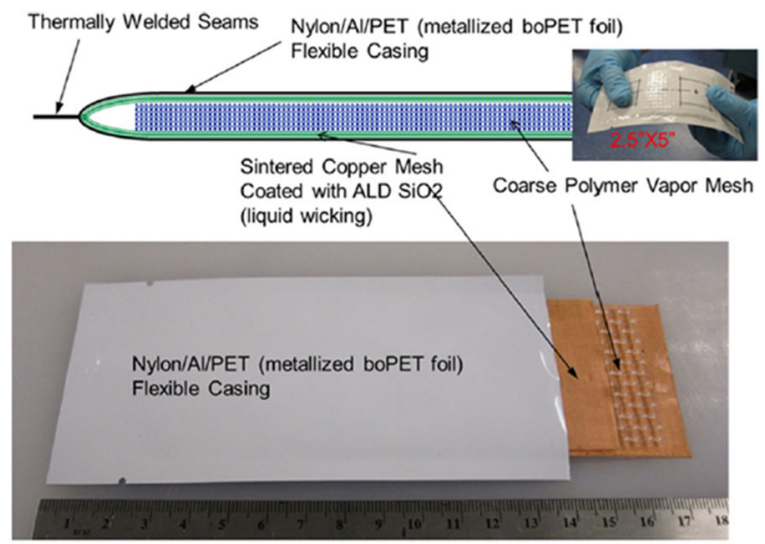

Fig. 3 Flexible vapor chamber

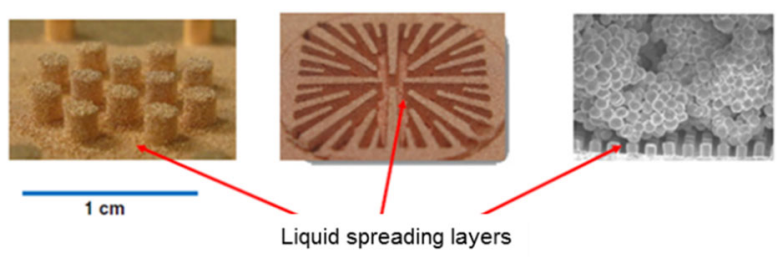

(a)

(b)

(c)

Fig. 4 Hybrid wick structures at the evaporator (a) Vertical columnar arteries; (b) Converging lateral arteries; (c) Powder bi-porous structure

Figure 5 shows the schematic of vapor chamber with copper powder vertical columnar arteries. The vapor chamber has length $120 \mathrm{~mm}$, width $70 \mathrm{~mm}$, and total height $4.6 \mathrm{~mm}$ (internal height $2.6 \mathrm{~mm}$ ), and the working fluid is water. The copper powder for the liquid spreading layer and the column are 50um and $150 \mathrm{um}$ respectively. It was claimed that for the heating area of $1 \mathrm{~cm} \times 1 \mathrm{~cm}$, the critical heat flux is about $380 \mathrm{~W} / \mathrm{cm}^{2}$, and the evaporator thermal resistance is about $0.05^{\circ} \mathrm{C} / \mathrm{W} / \mathrm{cm}^{2}$.

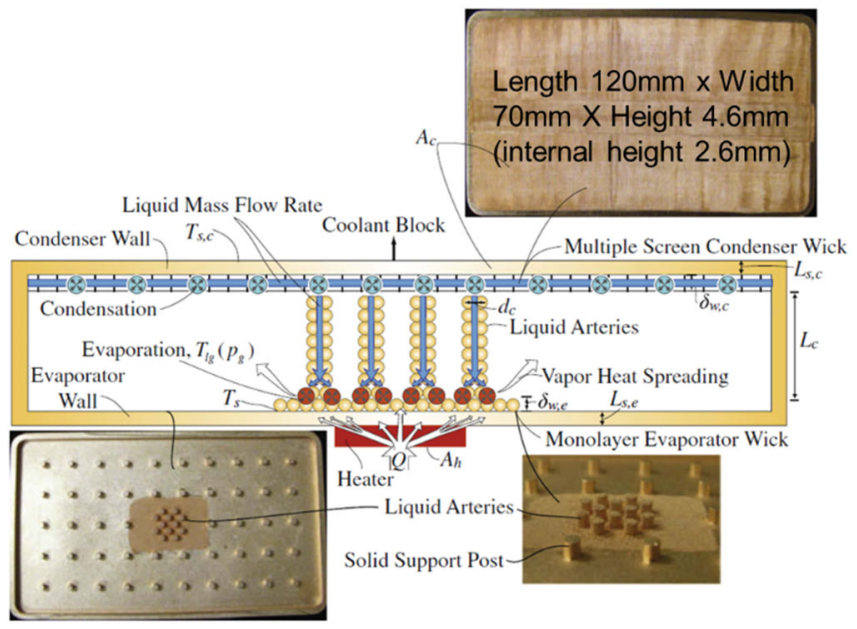

Fig. 5 Schematic of vapor chamber with powder vertical columnar arteries 
Figure 6 shows author's vapor chamber. It has length $105 \mathrm{~mm}$, width $60 \mathrm{~mm}$, and total height $0.35 \mathrm{~mm}$ (internal height about $0.2 \mathrm{~mm}$ ). Screen mesh was used as wick structure. The pattern of the wick structure varies depend mainly on the location of the heating area. For maximize the performance, it is essential to design the pattern to have the balance and uniform flow distribution of liquid and vapor.
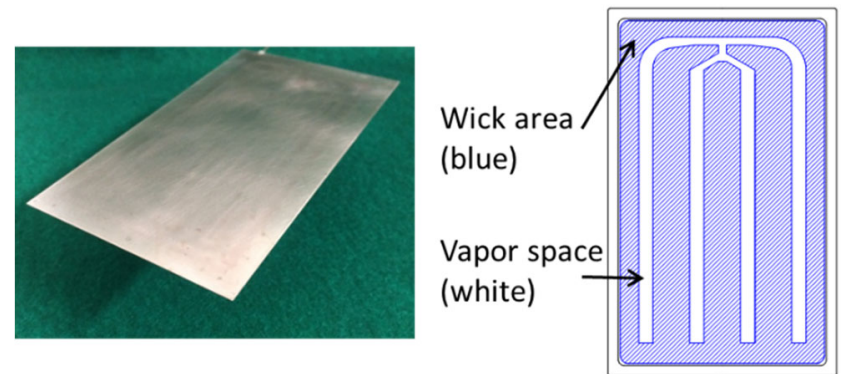

Fig. 6 Vapor chamber \#1 developed by M. Mochizuki ${ }^{\mathrm{a}}$ \& T. Nguyen ${ }^{\mathrm{b}}$

Figure 7 shows thermal spreading resistance comparison between thin vapor chamber and the graphite sheet of exact same dimensions. The graphite sheet claimed to have the in-plane thermal conductivity of approximately $800 \mathrm{~W} / \mathrm{m} . \mathrm{K}$. The spreading thermal resistance (Rsp) is defined in Eq. (1). The heating area is $10 \mathrm{~mm} \times 10 \mathrm{~mm}$ located at T2. The test was carried out in a vertical top heat configuration, and natural air convection cooling in a temperature controlled environment. Results in Fig. 7 shows that the vapor chamber spreading is at least 4 times better than graphite sheet.
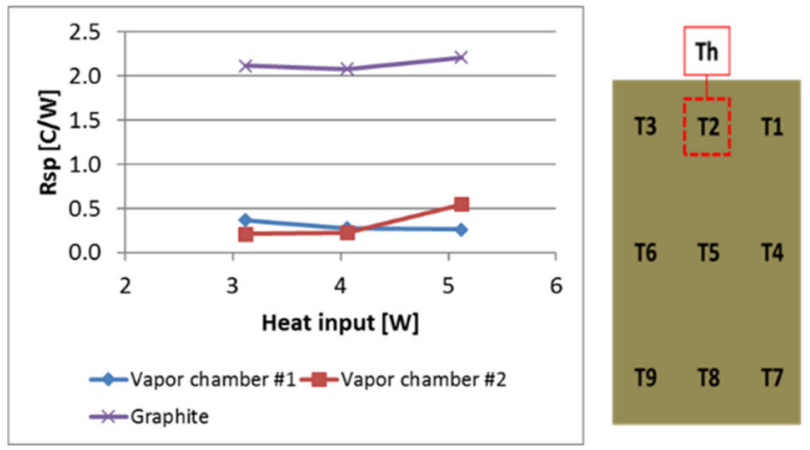

Fig. 7 Spreading thermal resistance comparison between vapor chamber and graphite sheet of same dimensions

$R s p=\frac{[T 2-\text { average }(T 1,3,4,5,6,7,8,9)]}{Q}$

where,

$Q=$ Heat input [W]

$R s p=$ Spreading thermal resistance $\left[{ }^{\circ} \mathrm{C} / \mathrm{W}\right]$

$T 2$ = Evaporator temperature $\left[{ }^{\circ} \mathrm{C}\right]$

$T 1, T 3$ to $T 9=$ Condenser temperature $\left[{ }^{\circ} \mathrm{C}\right]$

Figure 8 shows another example of thermal performance comparison between thin vapor chamber and the combination of Copper plate and graphite sheet. The vapor chamber is $100 \mathrm{~mm} \times 70 \mathrm{~mm}$ and $0.4 \mathrm{~mm}$ thick, whereas Copper plate and graphite sheet has same foot print but with thickness $0.2 \mathrm{~mm}$ and $0.05 \mathrm{~mm}$ respectively. The heating area is $10 \mathrm{~mm} \mathrm{x}$ $10 \mathrm{~mm}$ located at T2. Figure $8(\mathrm{~b})$ shows the vapor chamber can reduce the heat source temperature by about $6-10^{\circ} \mathrm{C}$, and at higher vapor chamber operating temperature gives higher improvement. Figure 8(c) shows the equivalent thermal conductivity comparison in favor of vapor chamber about 4-8 times better. The equivalent thermal conductivity was calculated using Eq. (2). The thermal image in Fig. 8(d) shows that vapor chamber helps spread the heat uniformly compared to the large temperature gradient of the Copper plate \& graphite sheet.
$K e=\frac{Q L e}{[\operatorname{average}(T 1,2,3)-\operatorname{average}(T 4,5,6)] W t]}$

where,

$\mathrm{Ke}=$ Equivalent thermal conductivity $[\mathrm{W} / \mathrm{mK}]$

$L \mathrm{e}=$ Equivalent thermal conductivity length $[\mathrm{m}]$

$Q=$ Heat input $[\mathrm{W}]$

$T 1$ to $T 6=$ Temperature of the evaporator top surface $\left[{ }^{\circ} \mathrm{C}\right]$

$t=$ Thickness of the vapor chamber or total thickness of the copper plate $\&$ graphite sheet $[\mathrm{m}]$

$W=$ Width of the vapor chamber or copper plate / graphite sheet [m]

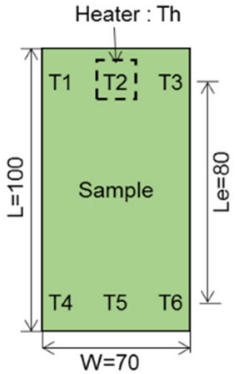

(a)

\begin{tabular}{|c|c|c|}
\hline Sample & $Q[\mathrm{~W}]$ & $\begin{array}{c}\text { Equivalent thermal } \\
\text { conductivity Ke [W/mK] }\end{array}$ \\
\hline \multirow{3}{*}{$\begin{array}{c}\text { Ultra thin } \\
\text { Vapor chamber }\end{array}$} & 3 & 4533 \\
\cline { 2 - 3 } & 4 & 7531 \\
\cline { 2 - 3 } & 5 & 7811 \\
\hline \multirow{3}{*}{$\begin{array}{c}\text { Cu plate }+ \\
\text { Graphite sheet }\end{array}$} & 6 & 9504 \\
\cline { 2 - 3 } & 3 & 1178 \\
\cline { 2 - 3 } & 5 & 1212 \\
\cline { 2 - 3 } & 6 & 1161 \\
\hline
\end{tabular}

(c)

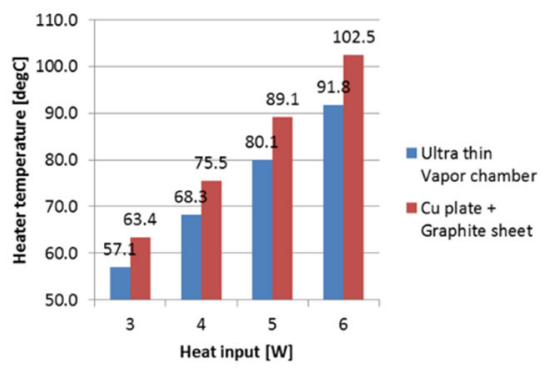

(b)

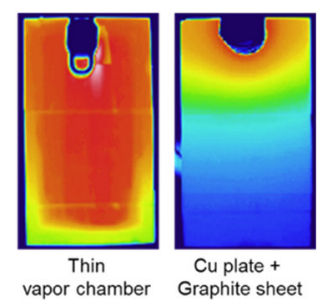

(d)
Fig. 8 Vapor chamber \#1 developed by M. Mochizuki ${ }^{\mathrm{a}}$ \& T. Nguyen ${ }^{\mathrm{b}}$

Figure 9 shows a good summary of various vapor chamber performance by Bar Cohen et al,. (2015). The abbreviation TGP means Thermal Ground Plane which operational principle is exact the same as vapor chamber. The summary indicated that the vapor chamber equivalent thermal conductivity is better than any known best material thermal conductivity.

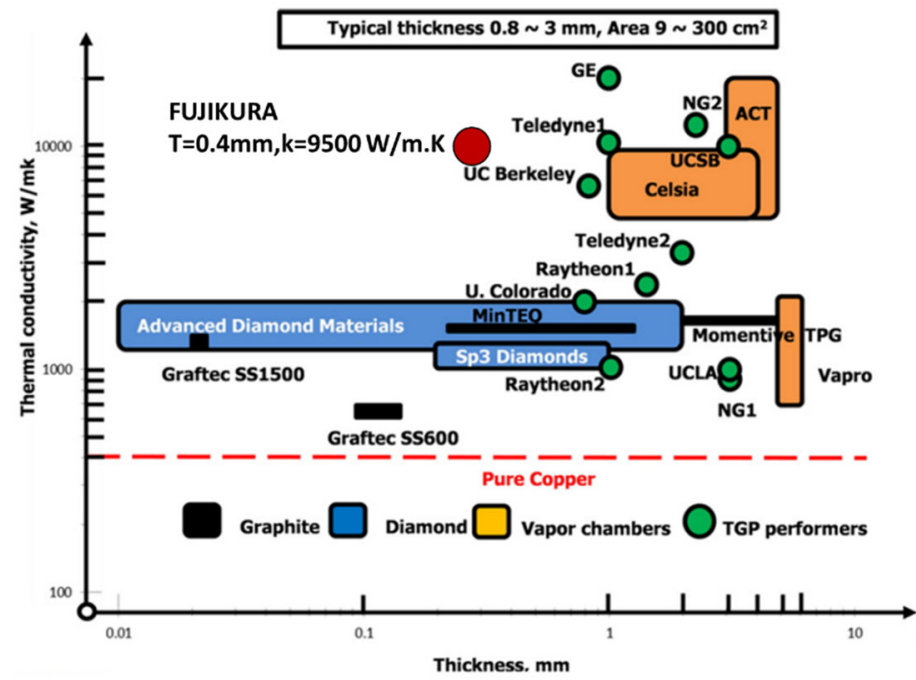

Fig. 9 Summary of vapor chamber performance 


\section{LIFE TIME RELIABILITY}

Heat pipe and vapor chamber are simple passive devices, and which are totally sealed and have no moving parts, therefore one would expected long life reliability, and it would be so if manufacturing correctly. Their life reliability can be degraded by the followings - the internal of the device is unclean; gases present due to improper vacuum and filling of working fluid; Incompatible of material and working fluid; Impurity of material and working fluid. In long term operating their thermal performance can be degraded as a result of (1) chemical reaction that generate non-condensable gases and/or (2) corrosion and erosion of the container and wick. The non-condensable gases (NCG) accumulate in the heat pipe or vapor chamber, forming a diffusion barrier to vapor flow and effectively reducing the condenser area available for heat transfer.

Table 1 Comparison of surface area ratio

\begin{tabular}{|l|l|l|l|l|}
\hline & $\begin{array}{l}\text { Heat pipe } \\
\text { diameter } 6 \mathrm{~mm} ; \\
\text { length } 140 \mathrm{~mm}, \\
\text { wall thickness } \\
0.3 \mathrm{~mm} .\end{array}$ & $\begin{array}{l}\text { Heat pipe } \\
\text { diameter } 2 \mathrm{~mm}, \\
\text { length } 140 \mathrm{~mm}, \\
\text { wall thickness } \\
0.3 \mathrm{~mm} .\end{array}$ & $\begin{array}{l}\text { Heat pipe } \\
\text { diameter } 2 \mathrm{~mm}, \\
\text { flatten to } 2.9 \mathrm{~mm}, \\
\text { length } 140 \mathrm{~mm}, \\
\text { wall thickness } \\
0.1 \mathrm{~mm} \text {, internal } \\
\text { height } 0.4 \mathrm{~mm} .\end{array}$ & $\begin{array}{l}\text { Vapor chamber } \\
\text { length } 140 \mathrm{~mm}, \\
\text { width } 70 \mathrm{~mm}, \\
\text { internal height } \\
0.2 \mathrm{~mm} .\end{array}$ \\
\hline $\begin{array}{l}\text { Internal surface } \\
\text { area }\left[\mathrm{m}^{2}\right]\end{array}$ & $2.375 \times 10^{-3}$ & $6.158 \times 10^{-4}$ & $7.56 \times 10^{-4}$ & $1.966 \times 10^{-2}$ \\
\hline $\begin{array}{l}\text { Internal volume } \\
{\left[\mathrm{m}^{3}\right]}\end{array}$ & $3.206 \times 10^{-6}$ & $2.155 \times 10^{-7}$ & $7 \times 10^{-8}$ & $1.96 \times 10^{-6}$ \\
\hline $\begin{array}{l}\text { Ratio surface } \\
\text { area to volume }\end{array}$ & 741 & 2857 & 10800 & 10029 \\
\hline Ratio to dia. $6 \mathrm{~mm}$ & 1 & 3.9 & 14.6 & 13.5 \\
\hline
\end{tabular}

The NCG can greatly affect the performance of vapor chamber since the ratio of surface area to internal space is large in comparison with traditional heat pipe. Table 1 shows a particular case study comparison between thin vapor chamber $(0.2 \mathrm{~mm}$ internal height $)$ and $6 \mathrm{~mm}$ round heat pipe - in this case the ratio of surface area to internal volume for vapor chamber can be a magnitude order higher than the round heat pipe. The more surface areas the higher chemical reaction between material and working fluid.

It is anticipated that most gas quantity generated at initial time as shown by Murakami et al., (1987). Figure 10(a) shows that most of gas quantity generated at the initial time, and very limited gas generation thereafter. These data were collected from Copper-water axial grooves heat pipe which has diameter $6.35 \mathrm{~mm}$ and total length $250 \mathrm{~mm}$ (heating length $50 \mathrm{~mm}$ ). There were total 60 samples tested at accelerated temperatures 40,60 , and $160{ }^{\circ} \mathrm{C}$. If the initial NCG generation can be removed, then it is expected that there will be little or no NCG in long term operating. To demonstrate this phenomenon, Murakami tested the heat pipe at the initial and measured temperature drop of heat pipe, then re-evacuated heat pipe and tested again. The results are shown in Fig. 10 (b) that heat pipe temperature drop remained constant after air reevacuation.

For computer, power devices, and electronic application, most of the vapor chamber would be made of copper and compatible working fluid water. Working fluid water was chosen due to its high latent heat and performance merit in the operating range $50-150^{\circ} \mathrm{C}$ applicable to computing devices. Also water is a friendly fluid to the environment. As mentioned before for the mobile devices, vapor chamber need to be thin and light which can be a problem for mechanical structure integrity due to copper material is soft. Therefore, a harder material which is compatible with water would be required. One of suitable material is Nickel.

In order to estimate the life time of Nickel-water combination, the Arrhenius correlation in Eq. (3) is used. The notations are - Ea is activation energy (Joules); $\mathrm{K}$ is Bolzman constant $\left(8.625 \times 10^{-5} \mathrm{eV} /{ }^{\circ} \mathrm{K}\right)$; Ttest is test temperature $\left({ }^{\circ} \mathrm{K}\right)$; and Tuse is operating temperature $\left({ }^{\circ} \mathrm{K}\right)$. Table 2 (Anderson, 1973) shows the activation energy for various material and fluid combination from the past literature. For Nickel-water combination the activation energy is about $10.3 \times 10^{-20}$ Joules.

Accelerator factor $=\mathrm{e}^{(-\mathrm{Ea} / \mathrm{K}) *(1 / \text { Ttest- } 1 / \text { Tuse })}$

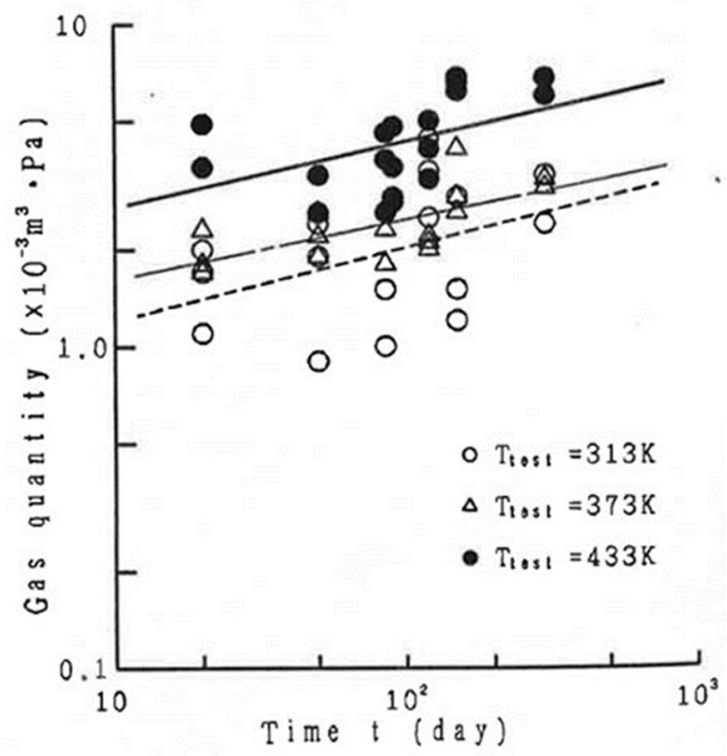

(a)

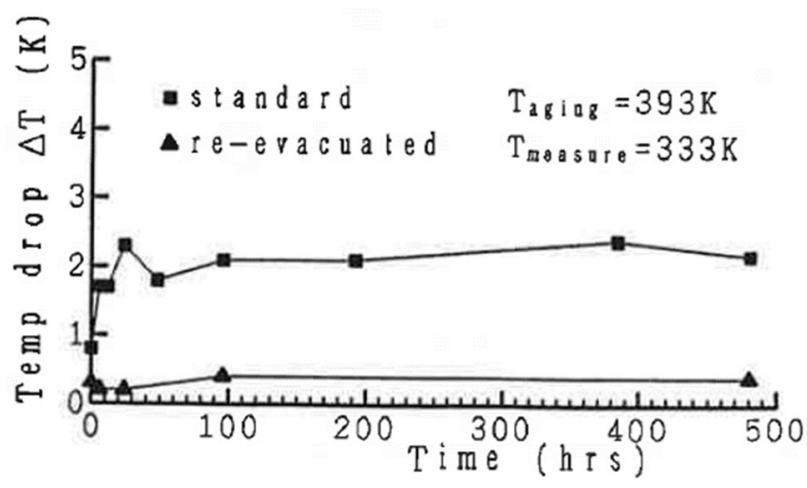

(b)

Fig. 10 Heat pipe copper-water life test data

Table 2 Activation energy for various material and fluid combination

\begin{tabular}{|c|c|c|c|}
\hline Material & Environment & $\begin{array}{c}\text { Temperature } \\
\left({ }^{\circ} \mathrm{C}\right)\end{array}$ & $\begin{array}{c}\text { Activation Energy } \\
\left(10^{-20} \text { Joules }\right)\end{array}$ \\
\hline Mild steel & Air & below 570 & 31.3 \\
\hline Stainless steel & Oxygen & $550-650$ & 20.6 \\
\hline Iron & Oxygen & $350-450$ & 15.7 \\
\hline Aluminum & Oxygen & $400-600$ & 25.9 \\
\hline Uranium & Air & & 15.3 \\
\hline Nickel & Oxygen & $310-345$ & 13.8 \\
\hline Nickel & Oxygen & $360-440$ & 14.6 \\
\hline Nickel & Oxygen & $500-1000$ & 24.2 \\
\hline Mild steel & $5-20 \%$ NaOH & $250-355$ & 10.4 \\
\hline Mild steel & $10 \% \mathrm{HCL}$ & $40-80$ & 10.1 \\
\hline $18 / 9$ Stainless steel & $\mathrm{H}_{2} \mathrm{SO}_{4}$ & -100 & 8.63 \\
\hline 304 Stainless steel & Distilled water & $38-149$ & 8.29 \\
\hline Iron & $10 \% \mathrm{HCL}$ & $40-90$ & 3.37 \\
\hline Lead & $10 \% \mathrm{HCL}$ & $40-110$ & 6.81 \\
\hline Aluminum & $70 \% \mathrm{HNO}{ }_{3}$ & $10-120$ & 8.47 \\
\hline Uranium & Water & & $5-10$ \\
\hline Nickel & Distilled water & $36-81$ & 10.3 \\
\hline \multicolumn{3}{|r}{} & \\
\hline
\end{tabular}

By use of Eq. (3) and assumes the operating temperature of $60^{\circ} \mathrm{C}$ for a continuous life time of 5 years, then the accelerated test time required for various temperature is show in Fig. 11. For example - If test at 
elevated temperature of $100^{\circ} \mathrm{C}$, the accelerating factor is about 10 times, and the test time required is about $4000 \mathrm{hrs}$. Whereas, if test at elevated temperature of $160{ }^{\circ} \mathrm{C}$, the accelerating factor would be about 180 times, and the test required is about $250 \mathrm{hrs}$.

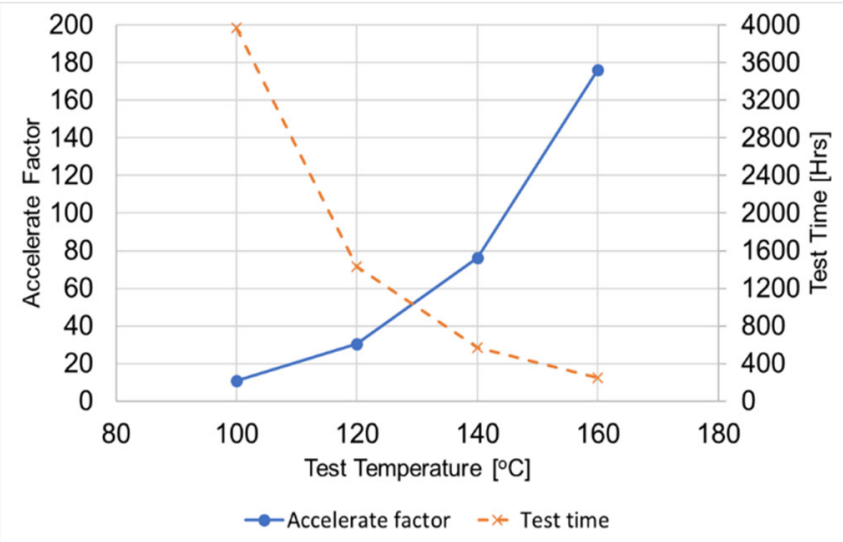

Fig. 11 Accelerator factor vs. temperature \& time for Ni-water

\section{APPLICATION}

Figure 12 shows general cooling technologies for cooling computer and electronic products. Heat pipe is now a commodity for cooling in computer desktop, laptop and ultrabook. In some cases, vapor chamber would be used if high performance heat dissipation required. Figure 13 shows examples of thin heat pipe use for cooling thin platform products such as computer tablet and smart phones. The thin heat pipe thickness is in the $0.5 \mathrm{~mm}$ level. The introduction of the $5 \mathrm{G}$ network smart phone device in 2019 , which would require higher dissipation, and possibly thin heat pipe is not efficient to transfer the heat away, unless multiple heat pipes are used. Recently, a smart phone company (LG) intends to use vapor chamber, as shown in Fig. 14, to more efficiently spread the heat in X-Y direction since it has larger surface area. This type of thin vapor chamber cooling solution may become necessary for thin high power devices.

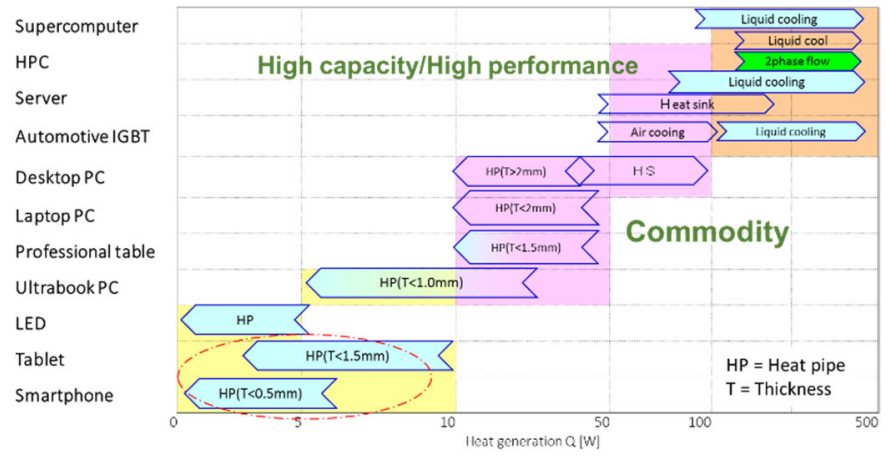

Fig. 12 General cooling technologies for computer and electronics products

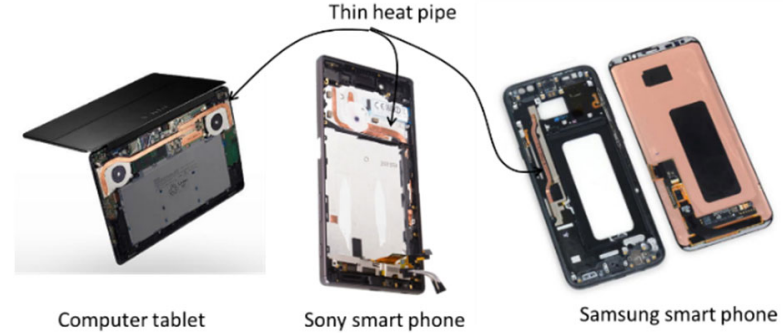

Fig. 13 Examples of use thin heat pipes for cooling thin platform products such as computer tablet and smart phone (images from internet)

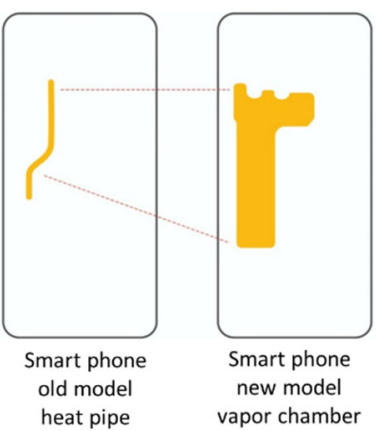

Fig. 14 Potential use of vapor chamber for $5 \mathrm{G}$ smart phone (image from internet)

\section{CONCLUSIONS}

- The minimum internal space height is limited to about $0.1 \mathrm{~mm}$ (ie. Minimum vapor chamber thickness about $0.3 \mathrm{~mm}$, assuming $0.1 \mathrm{~mm}$ thickness for top and bottom plates. Required further investigation on how to integrate wick into $0.1 \mathrm{~mm}$ plate total thickness).

- The maximum heat transfers for $0.1 \mathrm{~mm}$ space height vapor chamber would be only few watts.

- For the current design and manufacturing of thin vapor chamber $0.3 \mathrm{~mm}$ thick, it is unlikely that there will be any significant improvement in the thermal performance. Maybe a nano-structure wick, improvement in hydrophilic in the evaporator, and hydrophobic in the condenser, are required for further performance enhancement.

- When the internal space height reduces, other limits such as viscous limit can have significant effect on heat transfer capability, therefore these limits need to be calculated and considered in the design.

- Vapor chamber equivalent thermal conductivity or heat spreading performance is much better than any known heat spreading / conducting material for the same form factor.

- Expectation is that thin vapor chamber may become increasingly necessary for cooling thin high power devices.

- Non-condensable gas (NCG) can have a profound bad effect on thin heat pipe and vapor chamber since the internal surface is large but internal volume is small, therefore, small amount of NCG can occupy large volume ratio.

\section{REFERENCES}

Anderson, W.T., 1973, "Hydrogen Evolution in Nickel-Water Heat Pipe," AIAA $8^{\text {th }}$ Thermophysics Conference, July 16-18, USA.

Bar-Cohen, A., Matin, K., Jankowski, N., and Sharar, D., 2015, “TwoPhase Thermal Ground Planes: Technology Development and Parametric Results," Journal of Electronic Packaging, 137, 010801. http://dx.doi.org/10.1115/1.4028890

Boreyko, J.B., and Chen, C.H., 2013, "Vapor Chambers with JumpingDrop Liquid Return from Superhydrophobic Condensers," International Journal of Heat and Mass Transfer, 61, 409-418. http://dx.doi.org/10.1016/j.ijheatmasstransfer.2013.01.077

Hwang, G.S., Nam, Y., Fleming, E., Dussinger, P., Ju, Y.S., and Kaviany, M., 2010, "Multi-Artery Heat Pipe Spreader: Experiment," International Journal of Heat and Mass Transfer, 53, 2662-2669. https://doi.org/10.1016/j.ijheatmasstransfer.2010.02.046

Li, Y., Zhou, W., He, J., Yan, Y., Li, B., and Zeng, Z., 2016, “Thermal Performance of Ultra-Thin Flattened Heat Pipes with Composite Wick Structure," Applied Thermal Engineering, 102, 487-499. 
$\underline{\text { http://dx.doi.org/10.1016/j.applthermaleng.2016.03.097 }}$

Mochizuki, M., 2019, "Micro and Miniature Heat Pipes and Vapor Chamber for Cooling Electronic Devices, " $8^{\text {th }}$ International Symposium on Micro \& Nano Technology, April 26-28, Qingdao, China.

Murakami, M., Arai, K., and Kojima, Y., 1987, "Statistical Prediction of Long-Term Reliability of Copper-Water Heat Pipes from Accelerated Test Data," $6^{\text {th }}$ International Heat Pipe Conference, May 25-29, Grenoble, France.
Ryan Lewis, 2016, "Ultra-Thin Thermal Ground Planes," Kelvin Thermal Technologies, ATW, Denver.

Sungtaek, J.Y., Kaviany, M., Nam, Y., Sharratt, S., Hwang, G.S., Catton, I., Fleming, E., and Dussinger, P., 2013, "Planar Vapor Chamber with Hybrid Evaporator Wicks for the Thermal Management of High-HeatFlux and High-Power Optoelectronic Devices," International Journal of Heat and Mass Transfer, 60, 163-169.

http://dx.doi.org/10.1016/i.ijheatmasstransfer.2012.12.058 